\title{
The prognostic significance of vitamin D deficiency in patients with COVID-19 pneumonia
}

\author{
Yildiz M, Senel MU, Kavurgaci S, Ozturk FE, Ozturk A \\ Health Sciences University Faculty of Medicine Atatürk Chest Diseases and Thoracic Surgery Training \\ and Research Hospital, Pulmonary Medicine Department, Ankara, Turkey. drayperi@yahoo.com
}

\begin{abstract}
BACKGROUND: Vitamin D has anti-inflammatory and immunomodulatory effects via the downregulation of pro-inflammatory cytokines. We aimed to demonstrate the effect of vitamin D levels on survival in COVID-19 patients.

MATERIALS AND METHODS: 207 COVID-19 patients were included in the study. Serum vitamin D levels were measured, and patients with levels $<20 \mathrm{ng} / \mathrm{ml}$ or 21 to $30 \mathrm{ng}$ received a single $300.000 \mathrm{IU}$ dose of vitamin D. RESULTS: Of 207 patients, 37 received vitamin D, while 170 did not. Demographic, radiologic and mean laboratory values were similar between the groups. The mean plasma vitamin $D$ level without vitamin $D$ support $(\mathrm{n}=170)$ was $50.82 \pm 16.12 \mathrm{ng} / \mathrm{ml}(30.28-81.35)$ vs. $16.98 \pm 6.2 \mathrm{ng} / \mathrm{ml}(4.20-28.30)$ in vitamin $\mathrm{D}$ group. The most remarkable finding were the mortality rates; while only 1 patient $(2.7 \%)$ died in the vitamin D group, 24 patients $(14.1 \%)$ died in no vitamin D supplementation group $(p=0.038)$.

CONCLUSION: Although a few retrospective studies put forth a relation between vitamin $D$ deficiency and COVID-19 course severity there is still paucity of data about the efficacy of vitamin supplementations in COVID-19 patients. A single $300.000 \mathrm{IU}$ dose of vitamin D seems to represent a useful, practical, and safe adjunctive approach for the treatment or prevention of COVID-19 (Tab. 1, Fig. 1, Ref. 30). Text in PDF www.elis.sk KEY WORDS: vitamin D, COVID-19, prognosis.
\end{abstract}

\section{Introduction}

Vitamin D is a steroid hormone that is endogenously synthetized from 7-dehydrocholesterol in the skin to its active form, i.e. 1,25-dihydroxyvitamin D3 (1,25 (OH) 2D3) under the effect of ultraviolet light (1). Vitamin D synthetized in the skin or obtained through diet is hydroxylated in the liver to 25-hydroxyvitamin D $(25(\mathrm{OH}) \mathrm{D})$, which is the measured vitamin in the serum (2). Vitamin D has immuno-modulatory properties and has been shown to alleviate acute pulmonary injury induced by lipopolysaccharides via downregulation of pro-inflammatory cytokines (3), and, in mice, by blocking the effects on angiopoietin (Ang)-2-Tie-2 signal pathway and renin-angiotensin pathway (4). In addition to its anti-inflammatory and immuno-modulatory effects, it has also been shown to directly prevent viral replication (5).

Severe acute respiratory syndrome - Coronavirus-2 (SARS CoV2) infection is a major global health problem with a wide range of clinical manifestations from asymptomatic infection to cytokine

Health Sciences University Faculty of Medicine Atatürk Chest Diseases and Thoracic Surgery Training and Research Hospital, Pulmonary Medicine Department, Ankara, Turkey

Address for correspondence: A. Ozturk, Assoc. Prof, Health Sciences University Faculty of Medicine, Ankara Ataturk Chest Disease and Chest Surgery Training and Research Hospital, Interventional Pulmonology Department, 06280, Kuscagiz - Keciören, Ankara, Turkey. storm and life-threatening acute respiratory distress syndrome (ARDS) (5). Currently, it is not possible to accurately predict these clinical manifestations or the prognosis on an individual basis. SARS $\mathrm{CoV}-2$ virus enters cells through angiotensin converting enzyme 2 (ACE2) receptors, which are found on the cells of the respiratory tract of the host (7). Acquired impairment of the renin-angiotensin system may lead to cytokine production that can cause ARDS (8).

The protective immune responses are responsible for eliminating the virus in the early phase of the infection, indicating the importance of strengthening the immune responses. As the diseases progresses, pulmonary inflammation and fibrosis develops due to the secretion of pro-inflammatory cytokines, i.e. interleukin (IL) 1 and IL 18 as well as due to the effect of activated macrophages and type $1 \mathrm{~T}$ and T helper (Th1) cells (9). In a recent study, vitamin $\mathrm{D}$ has been reported to reduce the likelihood of developing COVID-19 symptoms, via induction of anti-microbial peptides (10). In this study, we examined the prognosis in COVID-19 patients who received vitamin D support.

\section{Materials and methods}

This study was undertaken at the tertiary chest disease and surgery training hospital with the inclusion of patients admitted to our unit between 01 Sep 2020 and 01 Oct 2020 with a diagnosis of COVID-19 infection. The diagnosis of COVID-19 was based on a real-time transcription polymerase chain reaction (RT-PCR) 
testing. Subjects $>18$ years of age who had a positive RT-PCR test result were eligible if they had thoracic computed tomography (CT) and/or chest $\mathrm{x}$-ray results available together with adequate clinical data in patient files or hospital database. Excluded patients were $<18$ years of age, without PA chest $x-$ ray or thoracic CT results available, or who had insufficient clinical data. Age, gender, concomitant conditions, laboratory results, and length of hospital stay were recorded. Chest $\mathrm{x}$-ray findings were evaluated in two categories as unilateral and bilateral findings. CT results were grouped according to the number of lobes involved. Serum vitamin $\mathrm{D}$ levels were measured, and those with a vitamin D level of $<20 \mathrm{ng} / \mathrm{ml}$ or 21 to $30 \mathrm{ng}$ received a single $300.000 \mathrm{IU}$ dose of vitamin D. Thus, the patients were grouped based on who did or did not receive vitamin D support. The need for intensive care unit admission, discharge status, and mortality was recorded in all patients.

Age, comorbidities, and laboratory results at admission were compared between patients who did or did not receive vitamin D support during the study period and also, mortality difference was evaluated.

\section{Statistical analysis}

Statistical analysis was performed using SPSS 21.0 software (IBM, Inc., Chicago, Illinois, USA). The compatibility of the data to normal distribution was investigated by the KolmogorovSmirnov test. Data showing continuous variables were expressed as mean \pm standard deviation or median (minimum-maximum), and categorical data were expressed as number and percentage (\%). Independent groups were compared using the Student T-test or Mann-Whitney U test whereas the Chi-square test was used for Categorical variables. A p value $<0.05$ was considered statistically significant.

\section{Results}

A total of 207 patients were included. Of these patients, 37 received vitamin $\mathrm{D}$, while 170 did not. Twenty-four $(64.9 \%)$ of those in vitamin D group were males, and 13 (35.1\%) were females, and the corresponding figures in no-Vitamin D group were $102(60 \%)$ and 68 (40\%), respectively. The mean age in patients who received vitamin D was $61.81 \pm 12.98$ years vs. $64.27 \pm 14.49$ years in those who did not receive vitamin D $(\mathrm{p}=0.342)$. The mean plasma vitamin D concentration in subjects without vita$\min \mathrm{D}$ support $(\mathrm{n}=170)$ was $50.82 \pm 16.12 \mathrm{ng} / \mathrm{ml}(30.28-81.35)$ vs $16.98 \pm 6.2 \mathrm{ng} / \mathrm{ml}(4.20-28.30)$ in those who received vitamin D.

Total white blood cell and lymphocyte count, neutrophil/lymphocyte ratio, C-reactive protein, D-dimer, and ferritin were not statistically different between the two groups (Tab. 1). Also, there were no significant differences in the proportion of patients with comorbid conditions $(78.4 \%$ vs $72.4 \%, p=0.585)$, as well as in oxygen saturation at presentation $(p=0.835)$. Furthermore, the two groups were not significantly different in terms of radiological pulmonary involvement and mean duration of hospital stay.

There were no patients requiring intensive care unit admission in the vitamin $\mathrm{D}$ group $(0 \%, \mathrm{n}=0)$, as compared to the group without vitamin D support $(7.1 \%, n=12)$, although the difference was not statistically significant. Only two patients in the vitamin D group $(5.4 \%)$ required advanced medical treatment (e.g. high

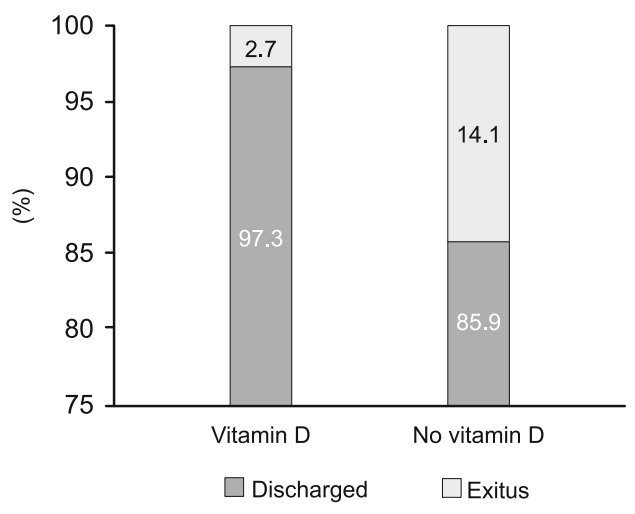

Fig. 1. Mortality rates in the groups. WBC - White blood cell count. 
dose steroids, plasma therapy, tocilizumab etc.), as compared to $15(8.8 \%)$ in the other group; however this difference was not statistically significant. The most remarkable result was found in mortality rates in the study; namely, in which only 1 patient $(2.7 \%)$ died in the vitamin D group and 24 patients $(14.1 \%)$ in the other group $(\mathrm{p}=0.038)$.

\section{Discussion}

A higher mortality rate was observed among the patients who did not receive vitamin D support in this study. Current evidence suggests that the main mechanism of pulmonary injury in $\mathrm{CO}$ VID-19 involves an unrestrained immune response leading to the "cytokine storm", with the net effect of dysfunctional coagulation and extensive tissue injury (11). Several cytokines such as tumor necrosis factor $\alpha(\mathrm{TNF}-\alpha)$, IL-1B, IL-8, and IL-12 are also involved in the pathogenesis of the disease, while IL 6 appears to be the most important component of the cytokine storm (12). IL-6 is produced by immune system cells (B and T lymphocytes, macrophages, dendritic cells, monocytes, mast cells) and is also synthesized by stromal cells and many non-lymphocyte cells, including fibroblast and endothelial cells. (13). The key activators for the secretion of IL-6 include IL- $1 \beta$ and TNF- $\alpha$ (14). Vitamin $\mathrm{D}$ is involved in the activity of many immune system cells including macrophages, B and T lymphocytes, neutrophils, and dendritic cells (15). Furthermore, vitamin D prevents the production of pro-inflammatory cytokines and increases the synthesis of anti-inflammatory cytokines (16). Evidence suggests that vitamin D may alleviate certain negative immunologic alterations such as increased IL- 6 and delayed interferon- $\gamma$ response (17).

A $25(\mathrm{OH}) \mathrm{D}$ level of less than $20 \mathrm{ng} / \mathrm{ml}$ is considered "deficiency, a level between 21-29 is defined as "insufficiency", and a level between 30 and $100 \mathrm{ng} / \mathrm{ml}$ is considered "normal" (18). In our study, patients with a 25 -hydroxyvitamin D level of $<30 \mathrm{ng} / \mathrm{ml}$ received vitamin $\mathrm{D}$ supplementation.

Calcitriol (1,25-dihydroxyvitamin D3) increases the expression of ACE2 through the ACE2/Ang(1-7)/MasR axis (19). ACE2 receptors on the host cell mediate SARS-CoV-2 infection. These findings initially suggested that vitamin D may actually predispose the individual to infection. However, vitamin D suppressed pro-inflammatory cytokines released from Th1 cells such as IL6, IL-8, IL-12, and IL-17 as well as it has also an important role in the killing of phagocytized bacteria through cathelicidin, an antimicrobial cationic peptide. Moreover, it has also been proven to provide defensive induction in the alveoli $(20,21,22)$. Studies from Europe showing an association between low vitamin D levels and mortality are also supportive of this view $(23,24)$. In a study by Kerget et al patients with low vitamin D were more likely to develop Macrophage Activation Syndrome (MAS) (25). In our study, although patients who did or did not receive vitamin D were not significantly different in terms of the need for intensive care unit admission and need for advanced medical and/or oxygen treatment, there were evident numerical differences.

In another study, Alipio et al divided a total of 40 subjects with COVID-19 infection into three groups based on their vitamin D levels (i.e. $>30 \mathrm{ng} / \mathrm{ml}, 21-29 \mathrm{ng} / \mathrm{ml}$, and $<20 \mathrm{ng} / \mathrm{ml}$ ), and 4 patient strata were also defined based on clinical status as mild, moderate, severe, and critically ill. Each standard deviation increase in serum $25(\mathrm{OH})$ D levels was associated with an almost 20 -fold higher likelihood of having mild disease (26). In a retrospective study by Frank H. Lau et al., a link between vitamin D deficiency and severe COVID-19 infection was also reported (27). Similarly, in our study, mortality rate was higher among patients who were not supplemented with vitamin D.

Until now, only few published studies have compared different vitamin D replacement regimens (28). Sayiner et al, did not find any significant differences in efficacy when comparing 50.000 IU of weekly vitamin D for a total duration of 6 to 8 weeks with a single $300.000 \mathrm{IU}$ replacement dose in a group of patients with vitamin D deficiency (29). Carnes et al. compared the efficacy of placebo and high dose vitamin $\mathrm{D}$ at a dose of either 300.000 or $150.000 \mathrm{IU}$, administered every 6 months over a one year period and found that these regimens can be safely used for the treatment of vitamin D deficiency (30). Theoretically a single $300.000 \mathrm{IU}$ of vitamin $\mathrm{D}$ can be taken orally by subjects in the general population or by patients treated on an outpatient or inpatient basis. In fact, generally a single $300.000 \mathrm{IU}$ dose of vitamin D is given in subjects or pregnant women with vitamin D deficiency. Also, this dose level was tested in some clinical studies involving HIV-infected patients (31). Similarly, we administered a single 300.000 IU dose of vitamin D orally to our patients with vitamin D deficiency or insufficiency.

In conclusion, clinical and cohort studies examining the role of vitamin D in preventing or reducing the severity of COVID-19 infections are relatively scarce in number. On the other hand, retrospective studies suggested that COVID-19 has a more severe course in patients with vitamin D deficiency. In line with these reports, a higher mortality rate was observed among our patients who did not receive vitamin D support. Based on these data as well as the reported anti-viral and anti-inflammatory effects, we believe that a single 300.000 IU dose of vitamin D may represent a useful, practical, and safe adjunctive approach for the treatment or prevention of COVID-19 disease, for which there are currently no definitive treatments or treatments that can alter the prognosis.

\section{References}

1. Van Etten E, Mathieu C. Immunoregulation by 1,25-dihydroxyvitamin D3: basic concepts. J Steroid BiochemMol Biol 2005; 97 (1-2): 93-101.

2. Ebert R, Schütze N, Adamski J, Jakob F. Vitamin D signaling is modulated on multiple levels in health and disease. Mol Cell Endocrinol 2006; 248: 149-159.

3. Greiller CL, Martineau AR. Modulation of the immune response to respiratory viruses by vitamin D. Nutrients 2015; 7: 4240-4270.

4. Kong J, Zhu X, Shi Y et al. VDR attenuates acute lung injury by blocking 9Ang-2-Tie-2 pathway and renin-angiotensin system. Mol Endocrinol 2013; 27: 2116-2125.

5. Teymoori-Rad M, Shokri F, Salimi V, Marashi SM. The interplay between vitamin D and viral infections. Rev Med Virol 2019; 29: e2032. 
6. Pascarella G, Strumia A, Piliego C et al. COVID-19 diagnosis and management: a comprehensive review. J Intern Med 2020; 288: 192-206.

7. Hoffmann M, Kleine-Weber H, Schroeder S, Kruger N, Herrler T, Erichsen S et al. SARS-CoV-2 Cell entry depends on ACE2 and TMPRSS2 and is blocked by a clinically proven protease inhibitor. Cell. 2020. https: //doi.org/10.1016/j.cell.2020.02.052.

8. Hrvoje Jakovac. COVID-19 and vitamin D - Is there a link and an opportunity for intervention? Am J Physiol Endocrinol Metab 2020; 318: 589.

9. Conti P, Ronconi G, Caraffa A, Gallenga CE, Ross R, Frydas I et al. Induction of pro-inflammatory cytokines (IL-1 and IL-6) and lung inflammation by Coronavirus-19 (COVI-19 or SARS-CoV2): anti-inflammatory strategies. J Biol Regul Homeost Agents 2020; 34. https: //doi. org/10.23812/CONTI-E.

10. Mitchell F. Vitamin-D and COVID-19: do deficient risk a poorer outcome? Lancet Diabetes Endocrinol. DOI: 10.1016/S2213-8587 (20)301832 (2020).

11. Cascella $\mathbf{M}$ et al. Features, Evaluation and Treatment Coronavirus (COVID-19) (StatPearls Publishing, Treasure Island, 2020.

12. Nile SH et al. COVID-19: pathogenesis, cytokine storm and therapeutic potential of interferons. Cytokine Growth Factor Rev 202; 53: 66-70.

13. Jones SA, Jenkins BJ. Recent insights into targeting the IL-6 cytokine family in inflammatory diseases and cancer. Nat Rev Immunol 2018; 18 (12): 773-789.

14. Hunter CA, Jones SA. IL-6 as a keystone cytokine in health and disease. Nat Immunol 2015; 16: 448-457.

15. Prietl B, Treiber G, Piber TR, Amrein K. Vitamin D and immune function. Nutrients 2013; 5: 2502-2521.

16. Martineau AR. Vitamin D supplementation to prevent acute respiratory tract infections: systematic review and meta-analysis of individual participant data. BMJ 2017; 356: 6583-6594.

17. Miroliaee AE, Salamzadeh J, Shokouhi S, Sahraei Z. The study of vitamin D administration effect on CRP and Interleukin-6 as prognostic biomarkers of ventilator associated pneumonia. J Crit Care 2018; 44: 300-305,

18. Michael FH, Neil CB, Heike AB et al. Endocrine Society. Evaluation, treatment, and prevention of vitamin D deficiency: an Endocrine Society clinical practice guideline. J Clin Endocrinol Metab 2011; 96 (7): 1911-1930

19. Kong J, Li YC. Effect of ANG II type I receptor antagonist and ACE inhibitor on vitamin D receptor-null mice. Am J Physiol Regul Integr Comp Physiol 2003; 285 (1): R255-R61.
20. McMurray DN, Bartow RA, Mintzer CL, Hernandez-Frontera E. 1990Micronutrient statusandimmunefunction in tuberculosis. Ann NY Acad Sci 587: 59-69.

21. Nonn L, Peng L, Feldman D, Peehl DM. Inhibition of $\mathrm{p} 38$ by vitamin $\mathrm{D}$ reduces interleukin-6 production in normal prostate cells via mitogenactivated protein kinase phosphatase 5: implications for prostate cancer prevention by vitamin D. Cancer Res 2006; 66 (8): 4516-4524.

22. Konya V, Czarnewski P, Forkel M, Rao A, Kokkinou E, Villablanca EJ et al. Vitamin D downregulates the IL-23 receptor pathway in human mucosal group 3 innate lymphoid cells. J Allergy Clin Immunol 2018; 141 (1): 279-292.

23. Grant WB, Lahore H, McDonnell SL, Baggerly CA, French CB, Aliano JL et al. Evidence that vitamin D supplementation could reduce risk of influenza and COVID-19 infections and deaths. Nutrients 2020; 12 (4): 988.

24. Ilie PC, Stefanescu S, Smith L. The role of vitamin D in the prevention of coronavirus disease 2019 infection and mortality. Aging Clin Exp Res 2020; 37 (7): 1195-1198.

25. Kerget B, Kerget F, Kiziltunç A, Koçak AO, Araz Ö, YilmazelUçar E, Akgün M. Evaluation of the relationship of serum vitamin D levels in COVID-19 patients with clinical course and prognosis. Tuberk Toraks 2020; 68 (3): 227-235.

26. Alipio M. Vitamin D Supplementation Could Possibly Improve Clinical Outcomes of Patients Infected with Coronavirus-2019 (COVID-2019). SSRN Electronic J 2020; 10.2139/ssrn.3571484.

27. Majumder LF, Torabi R, Saeg R, Hoffman F, Cirillo R, Greiffenstein JP. Vitamin D Insufficiency is Prevalent in Severe COVID-19. 2020. DOI: $10.1101 / 2020.04 .24 .20075838$.

28. Adams JS, Hewison M. Update in vitamin D. J ClinEndocrinolMetab 2010; 95: 471-478. 8. Ross AC. The 2011 report on dietary reference intakes for calcium and vitamin D. Public Health Nutr 2011; 14 : 938-939.

29. Sayiner MAr, Gülgün T, Sule K, Tülay Sargin M. Comparison of Different Vitamin D Replacement Modalities in Vitamin D-Deficient Patients. Turk J Endocrinol Metab 2016; 20: 6-9.

30. Carnes J, Quinn S, Nelson M, Jones G, Winzenberg T. Intermittent high-dose vitamin D corrects vitamin D deficiency in adolescents: A pilot study. Eur J Clin Nutr 2012; 66: 530-532.

Received March 11, 2021. Accepted March 25, 2021. 